\title{
COMMENTARIES
}

\section{We Need a Taxonomy of Working Memory}

\author{
Anastasia Kiyonaga \\ Helen Wills Neuroscience Institute, University of California, Berkeley, CA, US \\ kiyonaga@berkeley.edu
}

\begin{abstract}
A vast and diverse literature describes the relationship between working memory and attention. That literature encompasses tests of the interactions between the two functions, comparisons of the processes underlying them, and theoretical formulations of the cognitive constructs. In a recent review, Oberauer (2019) reins in this varied work to create a roadmap for future research. Here, I delineate several additional considerations to guide the evaluation and development of research into working memory and attention. Namely, working memory is a complex construct that can entail many processes and take on several meanings. Research and theory about working memory - and its relation to attention-must consider what particular demands are being tapped, what type of information is being operated on, and what goal is ultimately at stake.
\end{abstract}

Keywords: Working memory; Attention; Cognitive Control

After recent years of widespread agreement that working memory (WM) and attention are related functions, Oberauer (2019) takes on the formidable task of organizing and evaluating the evidence for this relationship. This review comes at an opportune time, as new work has highlighted the separability of WM and attention, and cautions against using the two interchangeably (Bae \& Luck, 2018; Harrison \& Bays, 2018; Mendoza-Halliday \& Martinez-Trujillo, 2017). Indeed, WM is defined by an obvious distinction from outwardly-oriented (i.e. 'perceptual') attention: WM content must be endogenously activated without current sensory input to evoke the representation. Therefore, to treat them as if they are identical only serves to glom more concepts into one, undermining the effort to understand component processes. While a critical interrogation of the relationship between WM and attention is essential to gain traction on these concepts, however, we should consider which routes for examining the relationship will generate testable predictions and theoretical progress.

\section{How should attention and working memory be defined and taxonomized?}

Oberauer aptly points out that 'attention' is a widely used term with diverse meanings. One of the most fundamental properties of attention, however, is that it is capacity-limited and therefore must be selective. In that sense, the theoretical distinction between conceptions of attention as a limited resource vs. a selection mechanism may be flawed; instead, those may be inter-twined properties that jointly describe attention-and they describe WM too. By examining the conditions that influence selection, for WM and perceptual attention, we may better understand what limits them both.

While Oberauer indicates that there is broad consensus as to the meaning of WM, that consensus belies both the complexity of the function and the varied usages of the term. Like attention, WM comprises multiple concepts, abilities, and processes. It can refer to a distributed system for short-term retention, a process of short-term maintenance, or a store for temporary representations. WM can operate in any sensory modality (e.g., verbal or visual) and holds information at several levels: WM maintains abstract goals that shape entire episodes, context-specific task rules, and concrete sensory content that feeds into meeting those rules. Tests of WM place variable demands on perceptual encoding, updating or manipulation, feature binding, and interference resolution, as well as memory retrieval and decision-making when memory is probed. WM content can vary in its motivational relevance and in the goal(s) it is ultimately being applied toward. These many sub-processes, content domains, and intentional states can engage distinct brain regions and networks, 
which likely underlies the currently fractured perspectives about how WM operates (e.g., Christophel, Klink, Spitzer, Roelfsema, \& Haynes, 2017; Constantinidis et al., 2018; Leavitt, Mendoza-Halliday, \& MartinezTrujillo, 2017; Lundqvist, Herman, \& Miller, 2018; Scimeca, Kiyonaga, \& D'Esposito, 2018; Xu, 2017). When we evaluate the relationship between the concepts of attention and working memory, therefore, we should recognize that the reciprocity between the two will depend on what processes and contents are at play.

\section{Under what circumstances should attention and working memory interact?}

WM performance is often unimpaired by concurrent perceptual attentional demands (and vice versa), fueling a common sense argument against the idea that the two are interdependent. However, this argument assumes (1) that all attentional demands are equally demanding, (2) that they should compete for the same resource (regardless of the sub-processes engaged), and (3) that resource competition is always evident in behavior. Rather, two interleaved WM tasks may impair each other more than a WM task paired with a perceptual task (cf. Fougnie $\&$ Marois, 2006), not because they rely on distinct mechanisms, but because the demand inherent to WM is greater than when the object of attention is activated by perceptual input. Moreover, we would expect WM and perceptual attentional dual-task demands to impact each other more when they both load on the same attentional sub-processes (cf. Woodman \& Chun, 2006). Finally, brain activity can reveal sensitivity to the interaction between WM and perceptual attention-even when behavior is unaffected-suggesting that control processes might sometimes compensate for the impacts of resource competition (e.g., Kiyonaga, Dowd, \& Egner, 2017).

The interactions between WM and perceptual attention should also vary with their overlap in representational content (cf. Kim, Kim, \& Chun, 2005). When perceptually attended stimuli are more similar to each other (e.g., in location or features) both neural and behavioral responses associated with individual items are degraded (Pelli \& Tillman, 2008; Reddy, Kanwisher, \& VanRullen, 2009). Likewise, visual WM is more disrupted by visual distraction from the same content category (Jha \& Kiyonaga, 2010; Sreenivasan \& Jha, 2007; Yoon, Curtis, \& D'Esposito, 2006), and the interplay between WM and visual attentional demands is continuously graded with the similarity between them (Kiyonaga \& Egner, 2016; Magnussen \& Greenlee, 1992; Rademaker, Bloem, De Weerd, \& Sack, 2015). Unrelated content may be trivial to segregate, therefore manifesting as absence of evidence for the interaction between WM and attention. To discover whether capacity constraints and selection mechanisms are truly distinct between these constructs, however, a fair comparison will account for the correspondence between the processes and content in each domain.

\section{Why characterize the relationship between attention and working memory?}

Oberauer's review underscores that there are many potential ways to catalogue and test the relationship between WM and attention. The most fruitful of these approaches may become clearer if we ask why it is important to examine that relationship in the first place. WM is more than a simple storage capacity-it is a ubiquitous contributor to many other cognitive processes and indices of success. Yet we understand very little about what determines its capacity. If we harness the rich history of attention research to illuminate (potentially) comparable WM functions, it may exponentially advance our understanding of WM. Following this approach, many studies have now shown that WM operates by the same principles that govern attentional selection, and that WM content can influence behavior as if it's being attended in the environment (Johnson et al., 2013; Kiyonaga \& Egner, 2014, 2016; Saad \& Silvanto, 2013). The comparison of WM to attention in this manner therefore creates testable predictions that can advance theories of both concepts.

Oberauer lists pressing questions to guide future investigations. This work should probe (1) the functional role of attentionally modulated sensory cortical signals, (2) how mnemonic and perceptual sensory content may be processed simultaneously, and (3) how representations and maintenance mechanisms across several levels of the processing stream may be integrated to explain the capacity and control of WM and attention. In daily life, we constantly rely on WM to achieve our goals, and we suffer to varying degrees from the simultaneous stream of demands for our attention in the environment. Rather than simply reflect a shortcoming in our cognitive capacity, however, the susceptibilities of WM to other demands may provide a window into the structure and function of the system. By examining when interactions between WM and perceptual attentional demands are present or absent, we can zero in on the conditions that optimize human performance. 


\section{Ethics and Consent}

Neither ethical approval nor consent were required for this work.

\section{Funding Information}

This work was supported by National Institute of Mental Health Award F32MH111204.

\section{Competing Interests}

The author has no competing interests to declare.

\section{References}

Bae, G. Y., \& Luck, S. J. (2018). Dissociable Decoding of Spatial Attention and Working Memory from EEG Oscillations and Sustained Potentials. Journal of Neuroscience, 38(2), 409-422. DOI: https://doi. org/10.1523/JNEUROSCI.2860-17.2017

Christophel, T. B., Klink, P. C., Spitzer, B., Roelfsema, P. R., \& Haynes, J. D. (2017). The Distributed Nature of Working Memory. Trends in Cognitive Sciences, 21(2), 111-124. DOI: https://doi.org/10.1016/j. tics.2016.12.007

Constantinidis, C., Funahashi, S., Lee, D., Murray, J. D., Qi, X.-L., Wang, M., \& Arnsten, A. F. T. (2018). Persistent Spiking Activity Underlies Working Memory. Journal of Neuroscience, 38(32), 7020-7028. DOI: https://doi.org/10.1523/JNEUROSCI.2486-17.2018

Fougnie, D., \& Marois, R. (2006). Distinct Capacity Limits for Attention and Working Memory Evidence From Attentive Tracking and Visual Working Memory Paradigms. Psychological Science, 17(6), 526-534. DOI: https://doi.org/10.1111/j.1467-9280.2006.01739.x

Harrison, W. J., \& Bays, P. M. (2018). Visual working memory is independent of the cortical spacing between memoranda. Journal of Neuroscience, 2645-17. DOI: https://doi.org/10.1523/JNEUROSCI.2645-17.2017

Jha, A. P., \& Kiyonaga, A. (2010). Working-memory-triggered dynamic adjustments in cognitive control. Journal of Experimental Psychology. Learning, Memory, and Cognition, 36(4), 1036-1042. DOI: https:// doi.org/10.1037/a0019337

Johnson, M. R., Higgins, J. A., Norman, K. A., Sederberg, P. B., Smith, T. A., \& Johnson, M. K. (2013). Foraging for Thought An Inhibition-of-Return-Like Effect Resulting From Directing Attention Within Working Memory. Psychological Science. DOI: https://doi.org/10.1177/0956797612466414

Kim, S. Y., Kim, M. S., \& Chun, M. M. (2005). Concurrent working memory load can reduce distraction. Proceedings of the National Academy of Sciences of the United States of America, 102(45), 16524. DOI: https://doi.org/10.1073/pnas.0505454102

Kiyonaga, A., Dowd, E. W., \& Egner, T. (2017). Neural Representation of Working Memory Content Is Modulated by Visual Attentional Demand. Journal of Cognitive Neuroscience, 29(12), 2011-2024. DOI: https://doi.org/10.1162/jocn_a_01174

Kiyonaga, A., \& Egner, T. (2014). The Working Memory Stroop Effect When Internal Representations Clash With External Stimuli. Psychological Science, 25(8), 1619-1629. DOI: https://doi. org/10.1177/0956797614536739

Kiyonaga, A., \& Egner, T. (2016). Center-Surround Inhibition in Working Memory. Current Biology, 26(1), 64-68. DOI: https://doi.org/10.1016/j.cub.2015.11.013

Leavitt, M. L., Mendoza-Halliday, D., \& Martinez-Trujillo, J. C. (2017). Sustained Activity Encoding Working Memories: Not Fully Distributed. Trends in Neurosciences, 40(6), 328-346. DOI: https://doi. org/10.1016/j.tins.2017.04.004

Lundqvist, M., Herman, P., \& Miller, E. K. (2018). Working Memory: Delay Activity, Yes! Persistent Activity? Maybe Not. Journal of Neuroscience, 38(32), 7013-7019. DOI: https://doi.org/10.1523/JNEUROSCI.2485-17.2018

Magnussen, S., \& Greenlee, M. W. (1992). Retention and disruption of motion information in visual shortterm memory. Journal of Experimental Psychology. Learning, Memory, and Cognition, 18(1), 151-156. DOI: https://doi.org/10.1037/0278-7393.18.1.151

Mendoza-Halliday, D., \& Martinez-Trujillo, J. C. (2017). Neuronal population coding of perceived and memorized visual features in the lateral prefrontal cortex. Nature Communications, 8, 15471. DOI: https://doi.org/10.1038/ncomms 15471 
Oberauer, K. (2019). Working Memory and Attention - A Conceptual Analysis and Review. Journal of Cognition, 2(1): 36, pp. 1-23. DOI: https://doi.org/10.5334/joc.58

Pelli, D. G., \& Tillman, K. A. (2008). The uncrowded window of object recognition. Nature Neuroscience, 11(10), 1129-1135. DOI: https://doi.org/10.1038/nn.2187

Rademaker, R. L., Bloem, I. M., De Weerd, P., \& Sack, A. T. (2015). The impact of interference on short-term memory for visual orientation. Journal of Experimental Psychology. Human Perception and Performance, 41(6), 1650-1665. DOI: https://doi.org/10.1037/xhp0000110

Reddy, L., Kanwisher, N. G., \& VanRullen, R. (2009). Attention and biased competition in multi-voxel object representations. Proceedings of the National Academy of Sciences, 106(50), 21447-21452. DOI: https://doi.org/10.1073/pnas.0907330106

Saad, E., \& Silvanto, J. (2013). How Visual Short-Term Memory Maintenance Modulates Subsequent Visual Aftereffects. Psychological Science, 24(5), 803-808. DOI: https://doi. org/10.1177/0956797612462140

Scimeca, J. M., Kiyonaga, A., \& D'Esposito, M. (2018). Reaffirming the Sensory Recruitment Account of Working Memory. Trends in Cognitive Sciences. DOI: https://doi.org/10.1016/j.tics.2017.12.007

Sreenivasan, K. K., \& Jha, A. P. (2007). Selective Attention Supports Working Memory Maintenance by Modulating Perceptual Processing of Distractors. Journal of Cognitive Neuroscience, 19(1), 32-41. DOI: https://doi.org/10.1162/jocn.2007.19.1.32

Woodman, G. F., \& Chun, M. M. (2006). The role of working memory and long-term memory in visual search. Visual Cognition, 14(4-8), 808-830. DOI: https://doi.org/10.1080/13506280500197397

Xu, Y. (2017). Reevaluating the Sensory Account of Visual Working Memory Storage. Trends in Cognitive Sciences, 21(10), 794-815. DOI: https://doi.org/10.1016/j.tics.2017.06.013

Yoon, J. H., Curtis, C. E., \& D'Esposito, M. (2006). Differential effects of distraction during working memory on delay-period activity in the prefrontal cortex and the visual association cortex. NeuroImage, 29(4), 1117-1126. DOI: https://doi.org/10.1016/j.neuroimage.2005.08.024

How to cite this article: Kiyonaga, A. 2019 We Need a Taxonomy of Working Memory. Journal of Cognition, 2(1): 35, pp. 1-4. DOI: https://doi.org/10.5334/joc.71

Submitted: 09 May 2019 Accepted: 20 May 2019 Published: 08 August 2019

Copyright: (c) 2019 The Author(s). This is an open-access article distributed under the terms of the Creative Commons Attribution 4.0 International License (CC-BY 4.0), which permits unrestricted use, distribution, and reproduction in any medium, provided the original author and source are credited. See http://creativecommons.org/ licenses/by/4.0/.

$\mathrm{u}[$ Journal of Cognition is a peer-reviewed open access journal published by Ubiquity OPEN ACCESS $\precsim$ 